\title{
THE IMPACT OF UNDERLYING MARKET CLOSURE ON FUTURES MARKET LIQUIDITY: EVIDENCE FROM CHINA
}

\author{
Wang Chun Wei and Alex Frino \\ University of Sydney, Australia
}

\begin{abstract}
This study investigates the trading activity of Chinese stock index futures, recently introduced at the open and close of the underlying trading. We document the impact of the underlying spot on the futures market liquidity as well as volatility as discussed in earlier works on market closure theory. Our empirical results support previous literature on the impact of the underlying, particularly during the open session, as a contagion effect, which is clearly at play. We find significant U-shaped patterns in liquidity factors and intraday volatility during open and close trades in the morning.
\end{abstract}

Key Words: Market microstructure, Market closure theory, Liquidity, Chinese futures market

JEL Classification: G14, G15

\section{Introduction}

Chang et al. (1995) argue that the price linkage between derivatives and cash implies that the closure of the underlying cash market, the spot, is likely to have a profound impact of the trading of a derivative. This impact on derivative trading is explained using King and Wadhwani's (1990) contagion model, which suggests that price behaviour in one market affects the behaviour in related markets as traders can draw inferences from multiple markets. More precisely, we suggest information transfer from spot equities market to futures market. This information transfer would however be disrupted, when the underlying market closes and therefore trading behaviour in the derivative market would be clearly affected.

Early attempts to understand the effects of market closure effect focus primarily on intraday volatility measures. Chang et al. (1995) examine intraday volatility and price changes of the S\&P 500 futures traded on the CME at around NYSE (i.e. underlying market) closure times. Their research was possible due to the continuation of the futures contract for 
15 minutes after NYSE closure. They document two separate U-shaped patterns for futures intraday volatility, before and after underlying spot market closure. They note that before the closure of underlying spot, when the underlying asset is trading, the futures volatility generally tends to reflect the intraday patterns of stock volatility, i.e. U-shaped. ${ }^{1}$ In futures trading after the underlying market closure time, the volatility drops significantly before increasing at the close. This second smaller U-shaped occurrence is proof of the contagion model as described in King and Wadhwani (1990). However, the U-shaped pattern itself is not explained via contagion.

Foster and Viswanathan (1990) explain the U-shaped pattern as being attributable to strategic trading models. They state that informed traders prefer to transact during periods when liquidity traders are most likely to trade to reduce execution costs - this happens most at market open and close times. Higher levels of liquidity trading at close may be due to several reasons, such as fund managers who might need to make trades at closing prices for fund purchases and redemption, and also investors wishing to hedge overnight positions. This explains the increase in volatility at futures closure time.

Daigler (1997) documents similar findings of a U-shaped volatility curve from futures contracts after underlying NYSE closure. Furthermore, in extension to Chang et al. (1995), Daigler (1997) finds that the intraday volatility of T-bond futures hold several U-shaped curves for respective day and night sessions, with the night sessions having a lower magnitude U-shaped curve than the day session. This is attributed to the lack of information flow when the underlying is closed.

More recently, studies extending to Asian markets have also been conducted. Fong and Frino (2001) document for Hang Seng index futures volatility changes around underlying market closure times. They find statistically significant declines in futures volatility following the close of the underlying market, followed by a rise at the futures close. This confirms results documented in the US. In this extension, another plausible explanation they raise for the pattern of intraday volatility is the decline of trading after underlying market closure, which would influence price volatility through bid-ask bounce. Fong and Frino (2001) argue that bid-ask bounce is less prevalent following underlying closure, therefore reducing any upward bias in the traditional volatility estimates of transaction prices. This was shown by

\footnotetext{
${ }^{1}$ See McInish and Wood (1992) for intraday stock volatility patterns.
} 
taking the difference between quoted price volatility relative to transaction price based volatility measures as in Chang et al. (1995).

Similarly, Huang (2002) studies the intraday patterns of volume as well as volatility and examines the market closure theory on the Taiwan stock index futures traded on the Taiwan Futures Exchange TAIFEX and Singapore Exchange Derivatives Trading SGX-DT. Huang (2002) notes that the TAIFEX opens and closes 15 minutes before and after underlying market trading, allowing the examination of the effect of an underlying cash market close on the futures market close. Whilst the SGX-DT futures exhibits a slight increase in volatility at the end of trading, the volatility on the TAIFEX futures, after a peak at the close of the underlying market, consistently drops towards the end of trading. It is reasoned that whilst SGX-DT futures have a large amount of market makers and scalpers closing their positions before futures market closure time, this is not the case for TAIFEX. This is perhaps due to higher transaction costs and stringent restrictions on foreign investors in TAIFEX trading.

This paper contributes to the literature on market closure theory in two ways: (i) the impact of liquidity on underlying market closure; and (ii) the focus of China's stock derivatives. We find scarce documentation of the impact of market closure on intraday liquidity, let alone with a focus on an emerging market such as China. Research in this area is important for understanding of the intraday dynamics of futures markets and also for institutional and regulatory purposes such as knowing the underlying impact of extended after hours derivative trading and periods where trading halts exist in the underlying market.

The remainder of this paper is structured as follows. First, we examine intraday price volatility and price changes, following traditional methods discussed in Chang et al. (1995). This is necessary, as it allows us to compare Chinese results with studies performed in the US. The second half of this paper drills deeper into liquidity factors such as trade frequency, size, spreads and depth around market closure for us to document effects of underlying market closure on liquidity. We then draw conclusions from our results and provide some explanation on the differences between our study on China and former studies on other markets. Our results therefore are new for an important emerging market for futures and also for the reason we extend the tests by incorporating a number of innovations. 


\section{Institutional Detail and Data}

This paper examines the trading behaviour of CSI 300 futures contracts in China. ${ }^{2}$ These contracts are based upon a capitalisation weighted index of the 300 largest companies listed in both the Shanghai and Shenzhen stock exchanges. The CSI 300 index linked futures contract was launched by the China Financial Futures Exchange ${ }^{3}$ on April 16th, 2010. It is China's only listed financial derivative at the time of writing. The contract itself has been mock traded since October 30th, 2006. The trading platform is best described as an electronic open limit order book - that is orders that match prices are automatically traded while unexecuted orders are left in the order book.

The underlying market trading hours for consecutive bidding in Shanghai and Shenzhen, ${ }^{4}$ are between 9:30am to 11:30am and from 1:00pm to 3:00pm. The pre-opening auction session runs from 9:15am to 9:25am, following which there is a 5 minute break prior to competitive bidding. Trading hours for the index linked futures contracts are from 9:15am to $3: 15 \mathrm{pm}$ with a lunch break from $11: 30 \mathrm{am}$ to $1: 00 \mathrm{pm}$. Similar to the futures contracts in Hong Kong, Taiwan and Singapore, the CSI 300 contract possess the timing characteristic of opening 15 minutes prior to the cash market and closing 15 minutes after the cash market. This provides a perfect setting for examining the impact of underlying closure in both the morning and afternoon sessions of trading.

The data used for this study consist both of intraday equal time spaced traded price series and tick data from Thomson Reuters Tick History, with a sample period from April 16th, 2010 to November 30th, 2010. For the analysis completed on intraday price volatility, we work with a total of 15,192 observations which record traded open, close, high and low at 5 minute intervals. In order to analyse intraday liquidity (as discussed in a later section of this paper), we use tick data, recording each traded price, traded volume, best bid price and volume, and best ask price and volume with a time stamp to the nearest 1/100th of a second. There is a total of 3,952,959 observations for our analysis.

\footnotetext{
${ }^{2}$ The underlying CSI 300 index is a capitalisation weighted index determined by the daily turnover and market capitalisation of the 300 largest companies listed on both the Shanghai and Shenzhen Stock Exchange. The futures contract size is the index multiplied by a factor of 300 yuan. This factor is designed to limit participation by retail investors by making each individual contract reasonably expensive. They have a tick of 0.2 index points and a daily limit of a $10 \%$ deviation from previous settlement price. The last trading or settlement day is on the 3rd Friday of the delivery month.

${ }^{3}$ The China Financial Futures Exchange was established with the country's two stock exhanges, Shanghai and Shenzhen stock exchange, in conjunction with three futures exchanges, Shanghai Futures Exchange, Dalian Commodity Exchange and Zhengzhou Commodity Exchange on September 8th, 2006.

${ }^{4}$ It is noted that Shanghai and Shenzhen are in the same time zone.
} 


\section{Intraday Volatility}

As discussed in Chang et al. (1995), Fong and Frino (2001) and Huang (2002) have focused on the study of intraday price volatility around underlying market closure times. Since Chinese stock index futures market is new, we begin by documenting their behaviour so as to provide information on what we know of previously studied markets.

To understand the impact of market closure on intraday price volatility in China, we divide each trading day into 5 minute intervals. We will not go into specifics of choosing a 5 minute frequency as opposed to say a 15 minute frequency or 1 minute frequency, but as is suggested by Chang et al. (1995), a 5 minute frequently adequately captures trading dynamics without being too data intensive.

Price volatility is measured using Parkinson's (1980) extreme value variance which was employed by Chang et al. (1995) due to its simplicity,

$$
\sigma_{t}^{2}=H_{t}-L_{t}
$$

which is the difference between the high minus the low for the given time interval. Wiggins (1991) argues Parkinson's estimator is significantly more efficient than close-to-close estimators.

We also apply the Garman-Klass estimate, which, as discussed in Huang (2002), is considered to be a superior measure, incorporating the open and close price for the time interval as well.

$$
\sigma_{t}^{2}=\frac{1}{2} \log \left(\frac{H_{t}}{L_{t}}\right)^{2}-(2 \log (2)-1) \log \left(\frac{C_{t}}{o_{t}}\right)^{2}
$$

The intraday price volatility measures are standardised per day for comparison i.e. $\sigma_{s t d, t}^{2}=\frac{\sigma_{t}^{2}-\frac{1}{n} \sum \sigma^{2}}{s}$ where $s$ is the sample standard deviation of the intraday volatility estimates. Standardisation is required because different days are not directly comparable - as the number of days to expiry has an effect on trading behaviour. With respect to the contagion model, there is an expectation that there will be a significant decline in the futures price volatility upon the closing of the underlying equity market. This can be tested using the null hypothesis, 
$H_{1}: \sigma_{\left[3: 00 p m_{\imath} 3: 05 p m\right)}^{2}=\sigma_{[2: 55 p m, 3: 00 p m)}^{2}$

Furthermore, to examine the patterns exhibited in the 15 minute after closure, we test if there is any changes to intraday volatility immediately after the underlying closure,

$H_{2}: \sigma_{\left[3: 05 p m_{\imath} 3: 10 p m\right)}^{2}=\sigma_{\left[3: 00 p m_{\imath} 3: 05 p m\right)}^{2}$

and whether there is a ramp up of volatility at futures closure.

$H_{3}: \sigma_{[3: 10 p m, 3: 15 p m)}^{2}=\sigma_{[3: 05 p m, 3: 10 p m)}^{2}$

Furthermore, let us compare at the closures, the difference in volatility at underlying closure to futures closure. This tests the significance of the impact of underlying closure in comparison to actual futures closure.

$H_{4}: \sigma_{\left[3: 10 p m_{\imath} 3: 15 p m\right)}^{2}=\sigma_{\left[2: 55 p m_{\imath} 3: 00 p m\right)}^{2}$

Unlike Chang et al. (1995), we are interested in analysing the effects of the morning period of trading. This is because the futures contract in China trades 15 minutes prior to the underlying market opening which is not the case for CME traded S\&P 500 futures. These hypotheses tests are performed, mirroring tests 1 to 4 .

$H_{5}: \sigma_{\left[9: 25 a m_{a} 9: 30 a m\right)}^{2}=\sigma_{\left[9: 30 a m_{2} 9: 35 a m\right)}^{2}$

$H_{6}: \sigma_{[9: 20 a m, 9: 25 a m)}^{2}=\sigma_{[9: 25 a m, 9: 30 a m)}^{2}$

$H_{7}: \sigma_{[9: 15 a m, 9: 20 a m)}^{2}=\sigma_{[9: 20 a m, 9: 25 a m)}^{2}$

$H_{\mathrm{g}}: \sigma_{\left[9: 15 a m_{2}, 9: 20 a m\right)}^{2}=\sigma_{[9: 30 a m, 9: 35 a m)}^{2}$

$\mathrm{H}_{5}$ tests if the impact of the underlying opening on futures market volatility. $\mathrm{H}_{6}$ and $\mathrm{H}_{7}$ tests whether volatility remains constant in the first 15 minutes of trading, when the underlying is still closed, and $\mathrm{H}_{8}$ examines if there are any notable differences in volatility in the futures market between derivative opening and underlying opening.

\section{Results on Intraday Volatility}


The International Journal of Banking and Finance, Volume 9 (Number 2), 2012: pages 26-43

In Table 1, we present volatilities based on both Parkinson and Garman-Klass measures. The t-statistics for each interval volatility estimate tests equality between the mean volatility for

That interval on that weekday and the mean midday volatility[9:45am, 11:30am) $\cup 1: 00 \mathrm{pm}, 2: 45 \mathrm{pm})]$. Furthermore, Table 2 presents twosample t-tests ${ }^{5}$ used to test the null hypothesis $\mathrm{H}_{1}$ to $\mathrm{H}_{8}$ for differences in intraday volatility due to market closure.

Table 1 documents standardised intraday volatilities at around underlying opening and closing. As expected, there is very little difference in the general trend of either GarmanKlass (GK) or Parkinson (P) measures. We note that intraday volatility is significantly higher than the average midday volatility (i.e. a standardised volatility of 1.7460 and 1.5149 for GK and $\mathrm{P}$ respectively, compared to 0.0017 and 0.0196 for the midday average) and continues to fall lower in the next two 5 minute intervals. For example, GK records the lowest standardised volatility of -0.1154 at the 5 minute interval preceding the underlying market opening. We document that after the underlying market opens at 9:30am, the standardised intraday volatility shoots up to 0.2691 and 0.2586 for GK and P respectively. Both measures show this to be statistically significant at the 0.05 level. This clearly illustrates a U-shaped pattern at the open, and confirms findings originally by Chang et al. (1995) and later by Fong and Frino (2001) for Hong Kong and Huang (2002) for Taiwan are also applicable to China. Information flow from the underlying market has clearly increased the volatility of China's derivative market.

Table 2 further verifies the behaviour in futures trading in the morning session by performing our hypothesis tests for $\mathrm{H}_{5}$ to $\mathrm{H}_{8}$. We note in particular that tests $\mathrm{H}_{5}, \mathrm{H}_{7}$ and $\mathrm{H}_{8}$ are statistically significant at the 0.05 level, suggesting that the volatilities in these intervals tested are not equal. Rejection of the null of $\mathrm{H}_{5}$ suggests that the volatility in the 5 minute period after underlying market opening is significantly higher than the volatility in the 5 minute period preceding underlying market opening. This is consistent with the view that information flow from the equity market should impact the futures market and generate higher intraday activity and subsequently volatility. Results from $\mathrm{H}_{7}$ show a strong decline in

\footnotetext{
${ }^{5}$ Two sample t-tests with unequal population variance is defined as $\frac{x_{1}-\bar{x}_{2}}{\sqrt{\frac{x_{1}^{2}}{n_{1}}+\frac{x_{2}^{2}}{n_{2}}}} \sim t_{k}$ where $\frac{1}{k}=\frac{\beta^{2}}{n_{1}-1}+\frac{(1-\beta)^{2}}{n_{2}-1}$ and $\beta=\frac{\frac{s_{1}^{2}}{n_{1}}}{\frac{x_{1}^{2}}{n_{1}}+\frac{x_{2}^{2}}{n_{2}}}$
} 
The International Journal of Banking and Finance, Volume 9 (Number 2), 2012: pages 26-43

volatility in the 2nd 5 minute interval after futures market opening in comparison to the first 5 minute interval. Significance of test 5 and 7 confirms with the U-shaped patterns in the volatility documented on Hang Seng index futures by Fong and Frino (2001) is also apparent with CSI 300 equity linked futures.

Table 1: Standardised intraday volatility

Coefficients and t-stats for standardised intraday volatility is provided using intraday 5 minute frequency traded price data under both the Garmin Klass (1980) and Parkinson (1980) methodology. The time series data obtained from Thomson Reuters Tick History is from April 16th, 2010 to November 30th, 2010. "Average midday" in the table represents the average 5 minute midday volatility from 9:45am to $2: 45 \mathrm{pm}$ excluding the 1.5 hour lunch break.

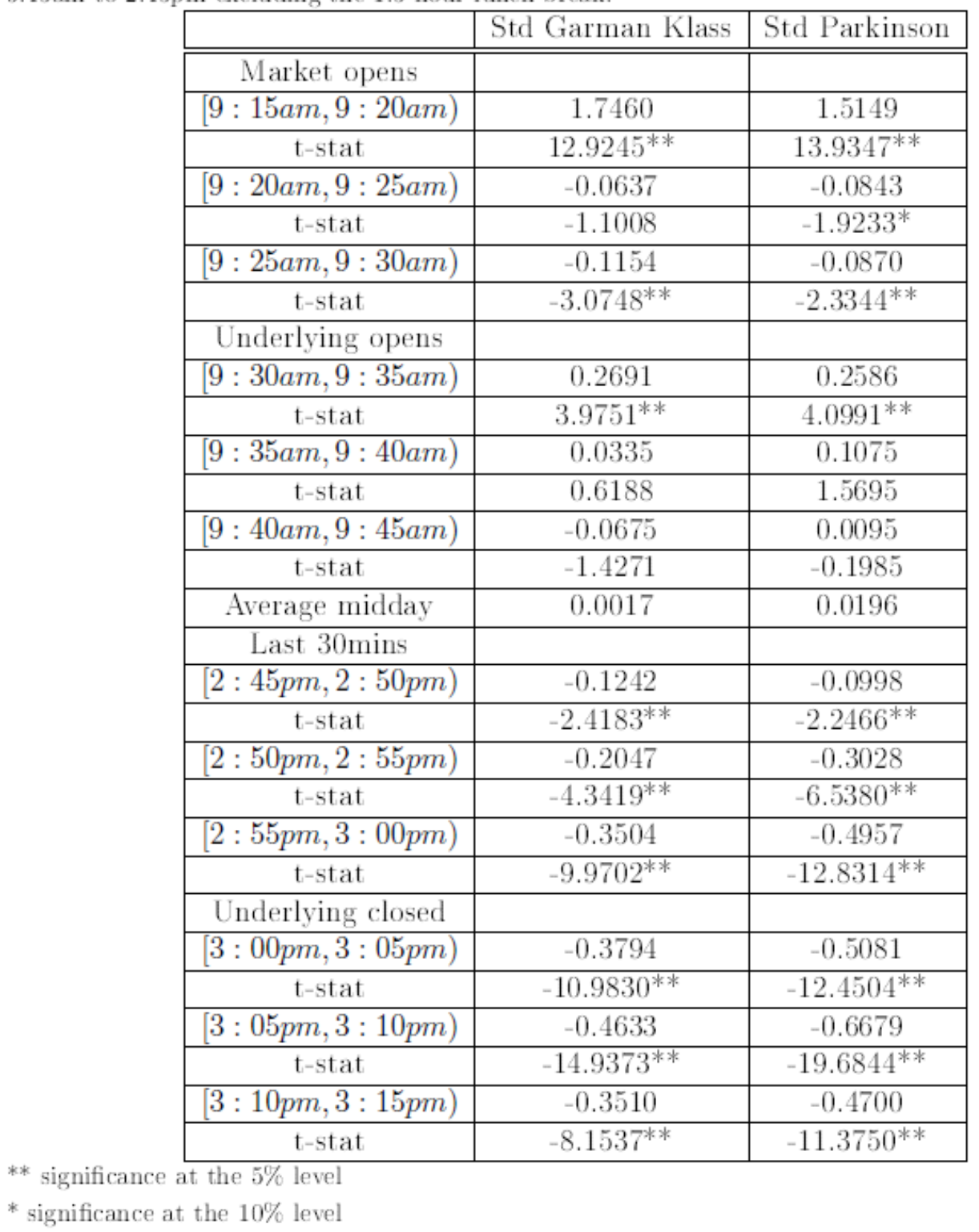

*** significance at the $5 \%$ level

In the afternoon session around underlying market closure, we document in Table $1 \mathrm{a}$ steady decline in intraday volatility. It is important to note that the decline in volatility starts not at underlying market closure, but in the periods prior to market closure. This decline 
continues unabated at market closure and in periods after the market closure. However, in the last 5 minute interval at futures closure, we note an uptick in volatility (a standardised figure of -0.3510 under GK and -0.4700 under $\mathrm{P}$ in comparison to -0.4633 and -0.6679 in the previous 5 minute interval).

However, this increase in volatility is still significantly lower than the average midday volatility in both Garman Klass and Parkinson measures (0.0017 and 0.0196 for GK and P respectively). The lower volatility in the afternoon documented in Table 1 in comparison to the midday average could be the direct result of the lack of new information in the underlying market at around closure. Certainly contagion stops completely at 3:00pm and intraday volatility is unlikely to increase at all until futures closure, where liquidity traders may increase activity as explained by Foster and Viswanathan (1990).

Our hypothesis tests for the afternoon session documented in Table 2 are less conclusive in comparison to the evidence from the morning session. We document a statistically significant increase in the last 5 minute interval, 3:10pm to $3: 15 \mathrm{pm}$, in comparison to the period 3:05pm to 3:10pm. This relationship is apparent in both GK and P measures, and is consistent with analysis conducted previously by Chang et al. (1995), Fong and Frino (2001) and Alsbed and Al-Khouri (2008).

Table 2: Intraday volatility - Hypothesis testing

Here we report two sample t-stats for our 8 hypothesis tests at determining the impact of underlying closure on intraday CSI 300 futures contract volatility over the period April 16th, 2010 to November 30 th, 2010. Hypothesis tests 1 to 4 focuses on the afternoon session from 2:55pm to 3:15pm. Hypothesis tests 5 to 8 focuses on the morning session of trading from 9:15am to 9:35am. Refer to equations (3) to $(10)$ for the definition of the tests.

\begin{tabular}{|l|c|c|}
\hline & Std Garman Klass & Std Parkinson \\
\hline \hline$H_{1: \sigma_{[3: 00 \mathrm{pm}, 3: 05 \mathrm{pm})}^{2}=\sigma_{[2: 55 \mathrm{pm}, 3: 00 \mathrm{pm})}^{2}}$ & -0.4468 & -0.1763 \\
\hline$H_{2: \sigma_{[3: 05 \mathrm{pm}, 3: 10 \mathrm{pm})}^{2}=\sigma_{[9: 00 \mathrm{pm}, 3: 05 \mathrm{pm})}^{2}}$ & -1.3350 & $-2.3463^{* *}$ \\
\hline$H_{3: \sigma_{[3: 10 \mathrm{pm}, 3: 15 \mathrm{pm})}^{2}=\sigma_{[3: 05 \mathrm{pm}, 3: 10 \mathrm{pm})}^{2}}$ & $1.6812^{*}$ & $2.8938^{* *}$ \\
\hline$H_{4: \sigma_{[3: 10 \mathrm{pm}, 3: 15 \mathrm{pm})}^{2}=\sigma_{[2: 55 \mathrm{pm}, 3: 00 \mathrm{pm})}^{2}}$ & -0.0079 & 0.3640 \\
\hline$H_{5: \sigma_{[9: 25 \mathrm{am}, 9: 30 \mathrm{am})}^{2}=\sigma_{[9: 30 \mathrm{am}, 9: 35 \mathrm{am})}^{2}}$ & $4.8369^{* *}$ & $4.3760^{* *}$ \\
\hline$H_{6: \sigma_{[9: 20 \mathrm{am}, 9: 25 \mathrm{am})}^{2}=\sigma_{[9: 25 \mathrm{am}, 9: 30 \mathrm{am})}^{2}}$ & -0.6770 & -0.0341 \\
\hline$H_{7: \sigma_{[9: 15 \mathrm{am}, 9: 20 \mathrm{am})}^{2}=\sigma_{[9: 20 \mathrm{am}, 9: 25 \mathrm{am})}^{2}}$ & $-16.7622^{* *}$ & $-16.2693^{* *}$ \\
\hline$H_{8: \sigma_{[9: 15 \mathrm{am}, 9: 20 \mathrm{am})}^{2}=\sigma_{[9: 30 \mathrm{am}, 9: 35 \mathrm{am})}^{2}}$ & $-13.4106^{* *}$ & $-12.6069^{* *}$ \\
\hline
\end{tabular}

*** significance at the $5 \%$ level

* significance at the $10 \%$ level 
Whilst we cannot reject the null hypothesis for test 2 under GK, Parkinson's measure for volatility shows a significant decline in volatility in period 3:05pm to $3: 10 \mathrm{pm}$ compared to period 3:00pm to 3:05pm. This suggests that a significant U-shaped intraday volatility pattern is apparent at market closure.

In conclusion, intraday volatility patterns in China are largely similar to findings by Huang (2002) for Taiwanese equity futures traded in Taiwan and Singapore and by Fong and Frino (2001) for the Hang Seng index futures.

\section{Intraday Liquidity}

The focus to date has been on the impact of market closure on intraday volatility. Here we extend these works with a particular focus on intraday liquidity. Whilst various studies have tried to understand the aspects of intraday market liquidity, however to the best of our knowledge, very few have focused on the effects of the closure of the underlying asset on the liquidity of the respectively traded futures.

Academics have used various definitions for liquidity. Schmukler et al. (2008) provide a general view on the definition of a liquid market as one in which 'market participants can promptly execute large volume transactions without significant price impact'. Liquidity is often associated with safety as it enables investors to sell in a timely manner with less slippage or price impact and therefore the fluctuations in liquidity in the intraday space is an important source of risk which needs to be studied. As argued by many academics, liquidity is multidimensional. Kyle’s (1985) seminal work describes market liquidity in three distinct aspects - tightness, depth and resiliency. Tightness is measured as the bid-ask spread, which is a proxy on the difference between the trade price and the actual price at execution. Depth is the volume which can be traded at the current level, and is proxied as the sum of the volume of the best bid and ask. Resiliency, discussed further in Muranaga (1998) and Muranaga and Shimizu (1999), is essentially the elasticity of the bidask spread.

Early empirical works by Admati and Pfleiderer (1988) identified U-shaped patterns in the average volume of shares, suggesting heavy trading at the beginning and end of the day, and light trading during the lunch period. Studies looking at intraday periodicities on liquidity in the form of a bid-ask spread was conducted by Chan et al. (1995) on stock 
options traded on the CBOE and their underlying assets on the NYSE. Like earlier works by McInish and Wood (1992), they document a U-shaped phenomenon for stock spreads. It can be argued that spreads are related to the perceived level of private information in the market. As large trades convey more information than small ones, we would expect bid-ask spreads to widen in times where levels of private information is high which arguably occurs at the opening and closing periods of the day. Ranaldo (2001) concludes that large spread size is associated with intense trading and higher trade volume, showing that for the Swiss exchange, intraday liquidity is characterised by a triple U-shaped curve due to the impact from market openings in the UK and US.

In this section, we focus on the impact of intraday liquidity due to underlying market closure. Therefore, instead of documenting variations across the day, we concentrate on changes in liquidity factors at the open and close of the underlying market. Proxies for three factors on liquidity are measured to document the impact, which we discuss below.

Trading Frequency: We document the number of trades in every 5-minute interval of trading on the futures contract is a proxy of how frequent it is traded during the day. Trade frequency is expected is rise as the contract nears expiry, hence the observations are standardised each day to provide consistency for analysis.

Tightness: Time-weighted bid-ask spreads as specified in McInish and Wood (1992) is used to give indication for market tightness. For a given time interval the time-weighted spread is defined as follows,

$$
\text { TWSpread }{ }_{t}=\frac{\sum_{i=1}^{\mathrm{n}} B A S_{i} t_{i}}{\sum_{i=1}^{\mathrm{m}} t_{i}}
$$

where $B A S_{i}$ is the quoted bid ask spread in the index as points, and $t$ is the amount of time the spread had existed for, before a new bid or ask was quoted. In this paper, we aggregate tradeby-trade data into 5 minute interval time-weighted bid-ask spreads. We standardise the result, similar to Chan et al. (1995), by subtracting the mean and dividing by the standard deviation for the day.

Depth: Market depth is estimated via intraday volume. In particular, we are interested in aggregating the volume of the best bid and ask price as follows,

$$
\text { Depth }_{t}=\frac{\text { BidVol }_{\mathrm{t}}+\mathrm{AskVol}_{\mathrm{t}}}{2}
$$


Similar to spreads, we time-weight depth into 5 minute intervals for analysis.

$$
\text { TWDepth } h_{t}=\frac{\sum_{i=1}^{n} D_{e p t h} t_{i}}{\sum_{i=1}^{n} t_{i}}
$$

This measure provides a good proxy at the ability for an investor to transact at the best bidask quotes given his or her transaction size. Likewise, for this paper, we calculate 5 minute time-weighted depth from using tick data.

\section{Results on Intraday Liquidity}

Table 3 presents the standardised intraday spreads and depth of equity linked futures trading. Focusing first on the standardised spreads, we document that bid-ask quotes start off extremely wide with a standardised spread of 1.0754 in the period 9:15am to 9:20am compared to the midday average of 0.0820 . This is suggestive that at market open traders cannot agree on an equilibrium price. This spread decreases in a significant manner in the next 10 minutes. The next peak occurs after cash market opening, which arguably new information is feed into the futures market as by King and Wadhwani's (1990) contagion model. In Table 4, we clearly have evidence to reject the null hypothesis for standardised spreads being equal in the morning session - i.e. $\mathrm{H}_{5}, \mathrm{H}_{6}, \mathrm{H}_{7}$ and $\mathrm{H}_{8}$.

A significant negative $\mathrm{t}$ statistic in $\mathrm{H}_{7}$ and a significant positive $\mathrm{t}$ statistic in $\mathrm{H}_{5}$ show a clear U-shaped pattern in the 15 minute period prior and post underlying trading. Therefore, bid-ask spreads start decreasing as futures market opens and increases during the time around underlying opening. Likewise for the afternoon session, the rejection of the null in $\mathrm{H}_{1}, \mathrm{H}_{2}$ and $\mathrm{H}_{3}$ in Table 4 means that spreads decrease after underlying closure and starts increasing prior to futures closure. This matches results presented by Fong and Frino (2001) for Hong Kong and Huang (2002) for Taiwan.

Table 3 also presents results on standardised bid-ask depth. We document higher levels of bid-ask depth in the open and close of the trading day in comparison to the midday average. Notably the standardised depth in the first 5 minutes and last 5 minutes of trading is 0.4539 and 0.6150 respectively, compared to the midday average of -0.0594 . Our tests $\mathrm{H}_{1}$ and $\mathrm{H}_{2}$ for depth in Table 4 show a statistically significant increase in the depth after underlying market closure at 3:00pm. Although we could not reject the null hypothesis for $\mathrm{H}_{3}$, the 
rejection of $\mathrm{H}_{4}$ at the 0.05 level clearly shows that the bid-ask depth in the last 5 minutes is much higher than in the period prior to underlying market closure.

The increase in depth and the decrease in spreads towards the end of the day is suggestive of an increase in aggressive bidding by market participants. Clearly, the risk of

Table 3: Standardised intraday spreads and depth

Coefficients and t-stats for standardised intraday bid-ask spreads and depth are provided using tradeby-trade data aggregated into time-weighted 5 minute intervals. Data obtained from Thomson Reuters Tick History is from April 16th, 2010 to November 30th, 2010. "Average midday" in the table represents the average 5 minute midday volatility from $9: 45 \mathrm{am}$ to $2: 45 \mathrm{pm}$ excluding the 1.5 hour lunch break.

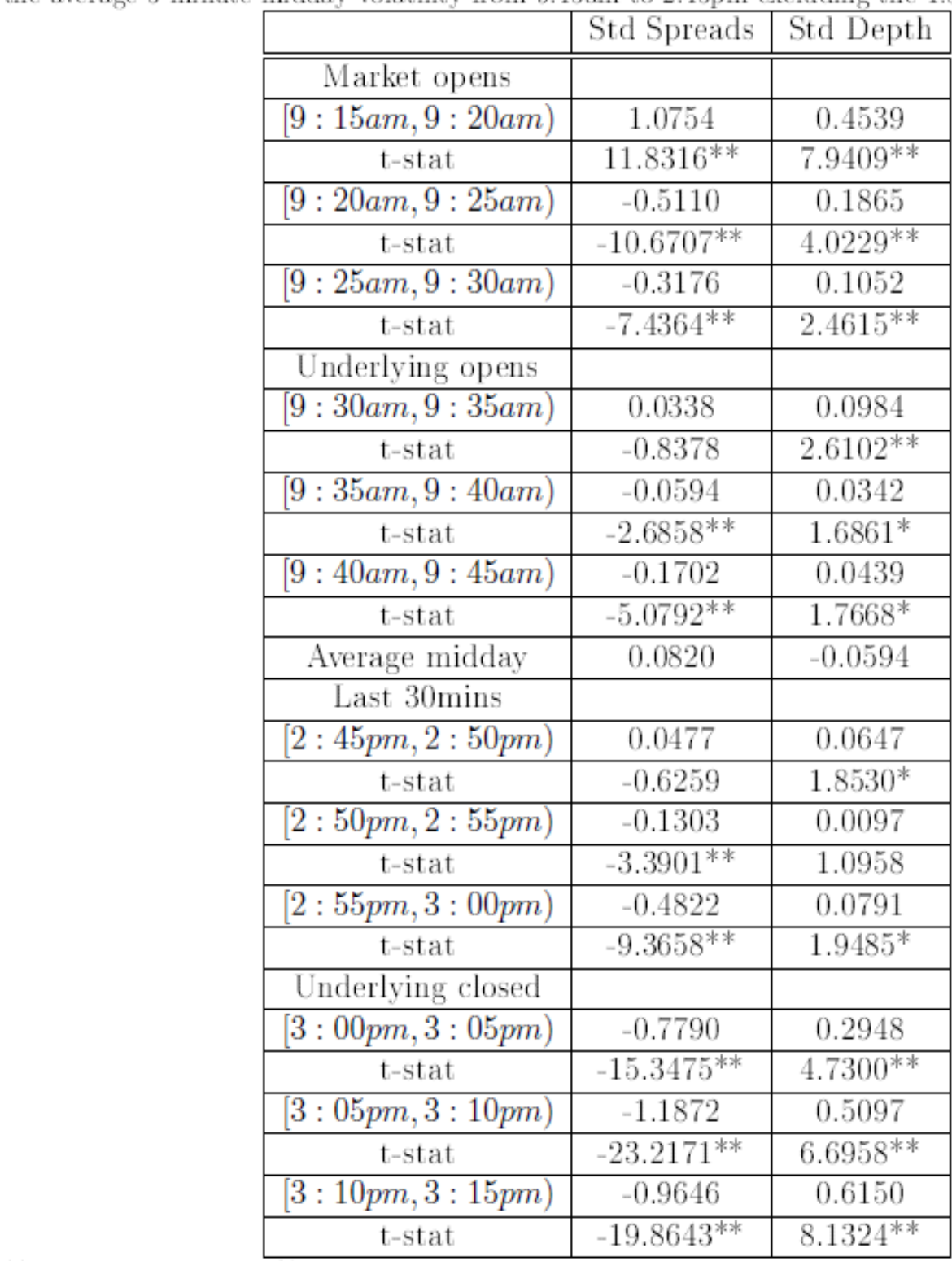

** significance at the $5 \%$ level

* significance at the $10 \%$ level

being picked-off towards the end of the trading day is lower due to the lack of information flow entering in the market. It is expected that any new information throughout the day would 
The International Journal of Banking and Finance, Volume 9 (Number 2), 2012: pages 26-43

have already been priced into the market. The reduced risk of being picked-off is further reflected in the declines in intraday volatility in around the same period (see Table 1). In conclusion, our results on bid-ask spreads and depth illustrate both King and Wadhwani (1990) and Foster and Viswanathan (1990) theories. Thus, there is decline in information after underlying closure, reducing the spread, and an increase in spreads as the direct result of strategic trading at the end of the day.

Table 4: Spreads and Depth - Hypothesis testing

Here we report two sample t-stats for our 8 hypothesis tests at determining the impact of underlying closure on intraday CSI 300 futures contract spreads and depth over the period April 16th, 2010 to November 30th, 2010. Hypothesis tests 1 to 4 focuses on the afternoon session from 2:55pm to $3: 15 \mathrm{pm}$. Hypothesis tests 5 to 8 focuses on the morning session of trading from 9:15am to 9:35am. Refer to equations (3) to (10) for the definition of the tests.

\begin{tabular}{|l|c|c|}
\hline & Std Spreads & Std Depth \\
\hline \hline$H_{1: \sigma_{[3: 00 \mathrm{pm}, 3: 05 \mathrm{pm})}^{2}}=\sigma_{[2: 5 \mathrm{spm}, 3: 00 \mathrm{pm})}^{2}$ & $-3.6058^{* *}$ & $2.0892^{* *}$ \\
\hline$H_{2: \sigma_{[3: 05 \mathrm{pm}, 3: 10 \mathrm{pm})}^{2}}=\sigma_{[3: 00 \mathrm{pm}, 3: 05 \mathrm{pm})}^{2}$ & $-5.2117^{* *}$ & $1.8965^{*}$ \\
\hline$H_{3: \sigma_{[3: 10 \mathrm{pm}, 3: 15 \mathrm{pm})}^{2}}=\sigma_{[3: 05 \mathrm{pm}, 3: 10 \mathrm{pm})}^{2}$ & $2.9319^{* *}$ & 0.8868 \\
\hline$H_{4: \sigma_{[3: 10 \mathrm{pm}, 3: 15 \mathrm{pm})}^{2}}=\sigma_{[2: 55 \mathrm{pm}, 3: 00 \mathrm{pm})}^{2}$ & $-6.0283^{* *}$ & $4.9061^{* *}$ \\
\hline & & \\
\hline$H_{5: \sigma_{[9: 25 \mathrm{am}, 9: 30 \mathrm{am})}^{2}=\sigma_{[9: 30 \mathrm{am}, 9: 35 \mathrm{am})}^{2}}$ & $4.4608^{* *}$ & -0.07557 \\
\hline$H_{6: \sigma_{[9: 20 \mathrm{am}, 9: 25 \mathrm{am})}^{2}=\sigma_{[9: 25 \mathrm{am}, 9: 30 \mathrm{am})}^{2}}$ & $2.5021^{* *}$ & -0.8977 \\
\hline$H_{7: \sigma_{[9: 15 \mathrm{am}, 9: 20 \mathrm{am})}^{2}=\sigma_{[9: 20 \mathrm{am}, 9: 25 \mathrm{am})}^{2}}$ & $-15.7557^{* *}$ & $-3.0052^{* *}$ \\
\hline$H_{8: \sigma_{[9: 15 \mathrm{am}, 9: 20 \mathrm{am})}^{2}=\sigma_{[9: 30 \mathrm{am}, 9: 35 \mathrm{am})}^{2}}$ & $-10.2311^{* *}$ & $-4.0170^{* *}$ \\
\hline
\end{tabular}

** significance at the $5 \%$ level

* significance at the $10 \%$ level

Table 5 presents standardised trade frequency and trade size around underlying opening and closing. Drawing attention to market open, trade frequency and size is notably higher than the midday average at the first 5 minutes of trading (9:15am to 9:20am) and similarly in the 5 minute period immediately after underlying opening. This observation along with our rejection of the null in tests $\mathrm{H}_{5}$ and $\mathrm{H}_{7}$ in Table 6 suggests clearly a U-shaped pattern in the 15 minutes, where frequency and size start off high, decline and then rise again at the opening of the underlying. This behaviour is consistent with our findings in the bid-ask spread and intraday volatility.

We also document a decrease in trade size and frequency is around the end of cash market close, as shown in Table 5. Furthermore, in the 15 minutes after cash market close, we observe that trade frequency and size increases as market participants hurry to trade prior to close. Unfortunately, we find that we are unable to reject the null at the 0.05 level for any differences in standardised trade size at market closure. However, we draw attention to $\mathrm{H}_{3}$ in 
Table 6 on standardised frequency, which documents a significant increase in trade frequency in the last 5 minutes of futures trading. This increase is explained well by Foster and Viswanathan (1990)'s strategic trading model as both informed and uninformed investors scramble to trade prior to closure.

Table 5: Standardised trade frequency and size

Coefficients and t-stats for standardised intraday traded frequency and size are provided using tradeby-trade data aggregated into time-weighted 5 minute intervals. Data obtained from Thomson Reuters Tick History is from April 16th, 2010 to November 30th, 2010. "Average midday" in the table represents the average 5 minute midday volatility from $9: 45$ am to $2: 45 \mathrm{pm}$ excluding the 1.5 hour lunch break.

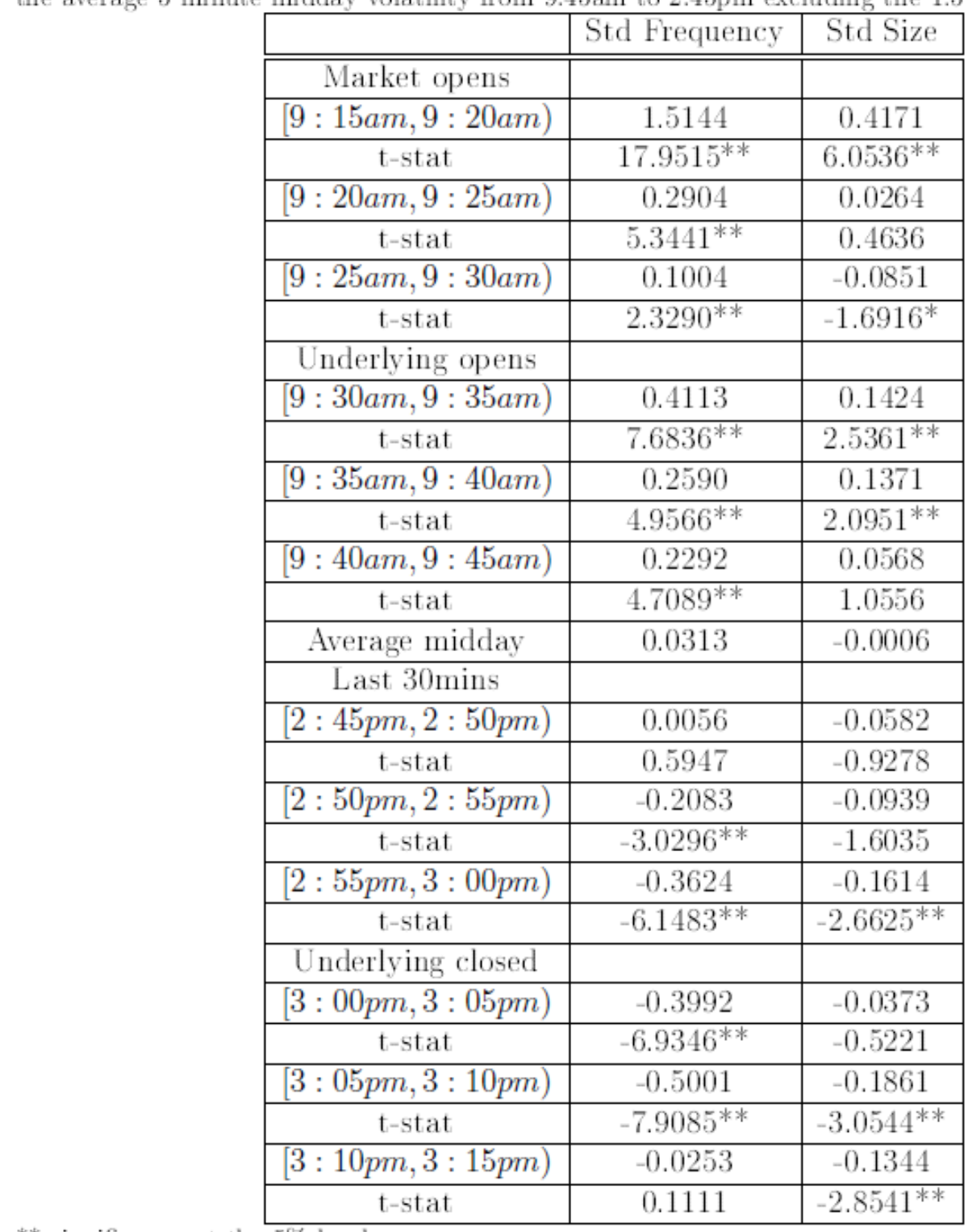

** significance at the $5 \%$ level

* significance at the $10 \%$ level

Despite observing a U shaped pattern near market close (see Table 5), what is different about China is that the decline in trades start before cash market closure. This would suggest market activity on the contracts falls towards the end of the day as there is no longer 
The International Journal of Banking and Finance, Volume 9 (Number 2), 2012: pages 26-43

any new information in the cash market. Activity only rises in the last 5 minutes due to liquidity investors interested in hedging overnight exposures and informed traders trying to pick off liquidity trades at market close.

Table 6 clearly reflects that trading frequency and size is more effected by the opening of the underlying cash market in the morning session of trading than the underlying market closure that the end of the day. It is noted that both frequency and size declines after the initial futures opening and later increases after the start of underlying trading - i.e. exhibiting the well documented U-shaped pattern.

Table 6: Trade Frequency and Size - Hypothesis testing Here we report two sample t-stats for our 8 hypothesis tests at determining the impact of underlying closure on intraday CSI 300 futures contract frequency and size over the period April 16th, 2010 to November 30th, 2010. Hypothesis tests 1 to 4 focuses on the afternoon session from 2:55pm to 3:15pm. Hypothesis tests 5 to 8 focuses on the morning session of trading from 9:15am to 9:35am. Refer to equations (3) to (10) for the definition of the tests.

significance at the $5 \%$ level

\begin{tabular}{|l|c|c|}
\hline & Std Frequency & Std Size \\
\hline \hline$H_{1: \sigma_{[3: 00 \mathrm{pm}, 3: 05 \mathrm{pm})}^{2}=\sigma_{[2: 55 \mathrm{pm}, 3: 00 \mathrm{pm})}^{2}}$ & -0.4858 & 1.3385 \\
\hline$H_{2: \sigma_{[3: 05 \mathrm{pm}, 3: 10 \mathrm{pm})}^{2}=\sigma_{[3: 00 \mathrm{pm}, 3: 05 \mathrm{pm})}^{2}}$ & -1.2692 & -1.6010 \\
\hline$H_{3: \sigma_{[3: 10 \mathrm{pm}, 3: 15 \mathrm{pm})}^{2}=\sigma_{[3: 05 \mathrm{pm}, 3: 10 \mathrm{pm})}^{2}}$ & $5.9322^{* *}$ & 0.6739 \\
\hline$H_{4: \sigma_{[3: 10 \mathrm{pm}, 3: 15 \mathrm{pm})}^{2}=\sigma_{[2: 55 \mathrm{pm}, 3: 00 \mathrm{pm})}^{2}}$ & $4.4294^{* *}$ & 0.3533 \\
\hline & & \\
\hline$H_{5: \sigma_{[9: 25 \mathrm{am}, 9: 30 \mathrm{am})}^{2}=\sigma_{[9: 30 \mathrm{am}, 9: 35 \mathrm{am})}^{2}}$ & $3.8504^{* *}$ & $3.0199^{* *}$ \\
\hline$H_{6: \sigma_{[9: 20 \mathrm{am}, 9: 25 \mathrm{am})}^{2}=\sigma_{[9: 25 \mathrm{am}, 9: 30 \mathrm{am})}^{2}}$ & $-2.3000^{* *}$ & -1.4532 \\
\hline$H_{7: \sigma_{[9: 15 \mathrm{am}, 9: 20 \mathrm{am})}^{2}=\sigma_{[9: 20 \mathrm{am}, 9: 25 \mathrm{am})}^{2}}$ & $-11.6495^{* *}$ & $-4.3271^{* *}$ \\
\hline$H_{8: \sigma_{[9: 15 \mathrm{am}, 9: 20 \mathrm{am})}^{2}=\sigma_{[9: 30 \mathrm{am}, 9: 35 \mathrm{am})}^{2}}$ & $-10.6482^{* *}$ & $-3.0844^{* *}$ \\
\hline
\end{tabular}

* significance at the $10 \%$ level

\section{Conclusion}

In conclusion, this study documents several interesting characteristics on the impact of underlying market closure times on the intraday liquidity and volatility. We find evidence for China’s futures market that intraday volatility is highest at the open and exhibits a U-shaped curve with an increase at the opening of the underlying, which is consistent with the existing literature on market closure as in King and Wadhwani's (1990) contagion model. Similar to Huang's (2002) assessment of Taiwan, volatility falls dramatically towards the end of the day, especially after market closures. We also document a small uptick at the last 5 minute interval 
which can be explained using Foster and Viswanathan (1990)'s strategic trading model. In terms of liquidity, we find that bid-ask spreads decline prior to underlying market closure, and continue to decline after closure. Bid-ask depth also increases in this period.

This study seems to suggest that market participants are bidding increasingly aggressively towards the end of the trading day, comforted by the fact that the risk of being picked off with limit orders are low given the falls in intraday price volatility at the same time. We attribute the fall in volatility to be the direct result of the lack of new information in the underlying spot market around closure times. Another finding is that morning effects on liquidity and volatility, when the underlying market open, were more statistically significant for the Chinese market than the afternoon effects as documented by Chang et al. (1995).

Author information: Submitting authors: Wang Chun Wei is staff member at the Discipline of Finance, Business School, University of Sydney. He is also working as a quantitative analyst at Regal Funds Management as part of a Capital Markets CRC grant. Email: wang.wei@regalfm.com. Alex Frino is a professor at the Discipline of Finance, Business School, University of Sydney. He is also CEO of Capital Markets CRC Limited. 
The International Journal of Banking and Finance, Volume 9 (Number 2), 2012: pages 26-43

\section{References}

Admanti, A. and P. Pfleiderer (1988) A theory of intraday patterns: volume and price volatility, Review of Financial Studies 1, 3-40

Alabed, M.F. and R. Al-Khouri (2008) The pattern of intraday liquidity in emerging markets: The case of the Amman Stock Exchange, Journal of Derivatives and Hedge Funds 14, $3 / 4,265-284$

Brock, W. and A. Kleidon (1992) Periodic Market Closure and Trading Volume: A model of Intraday Bids and Asks, Journal of Economic Dynamics and Control 16, 451-489

Chang, E.C., Jain, P.C. and P.R. Locke (1995) S\&P 500 index futures volatility and price changes around the NYSE close, Journal of Business 68, 61-84

Daigler, R.T. (1997) Intraday futures volatility and theories of market behaviour, The Journal of Futures Markets 17, 45-74

Foster, F.D. and S. Viswanathan (1990) A theory of intraday variations in volume, variances, and trading costs in security markets, Review of Financial Studies 3, 593-624

Fong, K. and A. Frino (2001)_Stock market closure and intraday stock index futures market volatility: contagion, bid-ask bias or both?, Pacific-Basin Finance Journal 9, 219-232

Garman, M. and M. Klass (1980) On the estimation of security price volatilities from historical data, Journal of Business 53, 67-78

Gourieroux, C., J. Jasiak and G. Le Fol (1997) Intraday market activity, working paper, CREST, Paris

Huang, Y.C. (2002) Trading activity in stock index futures markets: the evidence of emerging markets, The Journal of Futures markets 22, 983-1003

King, M.A. and S. Wadhwani (1990) Transaction of volatility between stock markets, Review of Financial Studies 3, 5-33

Kyle, A. (1985) Continuous auctions and insider trading, Econometrica 53, 1315-1335

McInish, T. H. and R.A. Wood (1990) An analysis of intraday patterns in bid/ask spreads for NYSE stocks, Journal of Finance 47, 753-764

Muranaga, J. (1998) Dynamics of market liquidity of Japanese stocks: an analysis of tick-bytick data of the Tokyo Stock Exchange, working paper, Institute for Monetary and Economics Studies, Bank of Japan, Tokyo

Muranaga, J. and T. Shimizu (1999) Market microstructure and market liquidity, working paper, Institute for Monetary and Economics Studies, Bank of Japan, Tokyo

Ranaldo, A. (2001) Intraday market liquidity on the Swiss stock exchange, Financial Markets and Portfolio Management 15 Issue 3, 309-327

Schmukler, S., Levy-Yeyati, E. and N. van Horen (2008) Emerging market liquidity and crises, Journal of the European Economic Association 6(2-3), 668-682

Von Wyss, R. (2004) Measuing and predicting liquidity in the stock market, doctoral dissertation, St. Gallen University

Wiggins, J.B. (1991) Empirical tests of the bias and efficiency of the extreme-value variance estimator for common stocks, Journal of Business 64, 417-432 